\title{
The 1997 eruption of Okmok Volcano, Alaska: a synthesis of remotely sensed imagery
}

\author{
M.R. Patrick ${ }^{a}, *$ J. Dehn ${ }^{a}$, K.R. Papp ${ }^{a}, Z$ Z. Lu ${ }^{b}$, K. Dean ${ }^{a}$, L. Moxey ${ }^{c}$, \\ P. Izbekov ${ }^{\mathrm{a}}$, R. Guritz ${ }^{\mathrm{d}}$ \\ a Alaska Volcano Observatory, Geophysical Institute, University of Alaska Fairbanks, 903 Koyukuk Drive, Fairbanks, AK 99775, USA \\ b US Geological Survey, EROS Data Center, SAIC, Sioux Falls, SD, USA \\ c Department of Geological Sciences, University of Florida, Gainesville, FL 32611, USA \\ d Alaska SAR Facility, Geophysical Institute, University of Alaska Fairbanks, 903 Koyukuk Drive, Fairbanks, AK 99775, USA
}

Received 2 October 2002; accepted 26 May 2003

\begin{abstract}
Okmok Volcano, in the eastern Aleutian Islands, erupted in February and March of 1997 producing a 6-km-long lava flow and low-level ash plumes. This caldera is one of the most active in the Aleutian Arc, and is now the focus of international multidisciplinary studies. A synthesis of remotely sensed data (AirSAR, derived DEMs, Landsat MSS and ETM+ data, AVHRR, ERS, JERS, Radarsat) has given a sequence of events for the virtually unobserved 1997 eruption. Elevation data from the AirSAR sensor acquired in October 2000 over Okmok were used to create a 5-m resolution DEM mosaic of Okmok Volcano. AVHRR nighttime imagery has been analyzed between February 13 and April 11, 1997. Landsat imagery and SAR data recorded prior to and after the eruption allowed us to accurately determine the extent of the new flow. The flow was first observed on February 13 without precursory thermal anomalies. At this time, the flow was a large single lobe flowing north. According to AVHRR Band 3 and 4 radiance data and ground observations, the first lobe continued growing until mid to late March, while a second, smaller lobe began to form sometime between March 11 and 12. This is based on a jump in the thermal and volumetric flux determined from the imagery, and the physical size of the thermal anomalies. Total radiance values waned after March 26, indicating lava effusion had ended and a cooling crust was growing. The total area $\left(8.9 \mathrm{~km}^{2}\right)$, thickness (up to $50 \mathrm{~m})$ and volume $\left(1.54 \times 10^{8} \mathrm{~m}^{3}\right)$ of the new lava flow were determined by combining observations from SAR, Landsat ETM+, and AirSAR DEM data. While the first lobe of the flow ponded in a pre-eruption depression, our data suggest the second lobe was volume-limited. Remote sensing has become an integral part of the Alaska Volcano Observatory's monitoring and hazard mitigation efforts. Studies like this allow access to remote volcanoes, and provide methods to monitor potentially dangerous ones.
\end{abstract}

(C) 2003 Elsevier B.V. All rights reserved.

Keywords: remote sensing; volcano monitoring; Advanced Very-High-Resolution Radiometer; Landsat; Synthetic Aperture Radar; Okmok

* Corresponding author. Present address: HIGP/SOEST, University of Hawaii, 1680 East-West Road, Honolulu, HI 96822, USA..

E-mail address: patrick@higp.hawaii.edu (M.R. Patrick).

\section{Introduction}

Okmok Volcano, on Umnak Island in the eastern Aleutians, erupted in February and March of 
1997 producing a 6-km-long lava flow and intermittent low-level ash plumes $(<9 \mathrm{~km}$ above sea level (asl)). Due to its remote setting and the short duration of activity, co-eruptive field data were limited to a single set of photographs taken on a serendipitous overflight of the island by National Oceanographic and Atmospheric Administration (NOAA) marine mammal researchers (J. Sease, personal communication). This dearth of field data, along with the lack of any seismic or geodetic network on the island, made remotely sensed imagery the sole source of information available to characterize the eruptive activity at a regular frequency and judge its hazard potential. Throughout the eruption, the Alaska Volcano Observatory (AVO) utilized real-time Advanced Very-High-Resolution Radiometer (AVHRR) data to analyze the dimensions of plumes and thermal anomalies in order to provide warnings for North Pacific air traffic as well as the town of Nikolski (population 35), $72 \mathrm{~km}$ west of the caldera, and the ranch on the former Fort Glenn military base $16 \mathrm{~km}$ east of the caldera (Dean et al., 1998; McGimsey and Wallace, 1999).

In order to refine our understanding of the nature of the eruption, remotely sensed data from a range of time periods and a variety of sources were compiled (Tables 1 and 2). For the pre-eruption period, Landsat 3 Multispectral Scanner (MSS) imagery, as well as several European Remote Sensing satellite (ERS-1 and ERS-2) Synthetic Aperture Radar (SAR) images, were acquired. The pre-eruption surface was characterized by a digital elevation model (DEM) created through SAR interferometry ( $\mathrm{Lu}$ et al., in press). Data acquired during the eruption were limited to AVHRR imagery, whose thermal infrared channels and high temporal resolution permitted quantitative heat flux analysis at a high frequency (Dean et al., 1998; Dehn et al., 2000). These data were re-examined in greater detail to extract as much information as possible about the course of the eruptive activity. Post-eruptive conditions were gleaned through a suite of post-eruption imagery, which included a Landsat 7 Enhanced Thematic Mapper Plus (ETM+) scene, SAR imagery from ERS-1 and ERS-2, Radarsat and Japanese Earth Resources Satellite (JERS) sensors, and recently collected high-resolution AirSAR DEM data (Moxey et al., 2001; Lu et al., in press). Together, these data offer the first complete picture of the 1997 eruption.

\section{Background}

Okmok Volcano lies within the northeastern portion of Umnak Island, at the eastern end of the Aleutian volcanic chain (Fig. 1). The caldera complex is the result of two caldera-forming eruptions, aged at 8200 and 2400 years BP, as well as subsequent post-caldera activity involving lava effusion and cone building (Byers, 1959; Black, 1975; Miller and Smith, 1987). The caldera measures approximately $10 \mathrm{~km}$ in diameter and con-

Table 1

Remotely sensed imagery

\begin{tabular}{llll}
\hline Period & Acquisition time(s) & Sensor & Type \\
& & & $\begin{array}{c}\text { Pixel size } \\
(\mathrm{m})\end{array}$ \\
Pre-eruption & August 3, 1983 & Landsat 3 MSS & Multispectral \\
Pre-eruption & April 10, 1994 & ERS-1 & SAR \\
Pre-eruption & October 26, 1995 & ERS-2 & SAR \\
Syn-eruption & $6-8$ times daily & AVHRR & Multispectral \\
Post-eruption & April 3, 1997 & ERS-2 & SAR \\
Post-eruption & April 7, 1997 & Radarsat-1 & SAR \\
Post-eruption & July 17, 1997 & ERS-2 & SAR \\
Post-eruption & August 2, 1997 & Radarsat-1 & SAR \\
Post-eruption & November 5, 1997 & JERS-1 & SAR \\
Post-eruption & August 17, 2000 & Landsat 7 ETM+ & Multispectral \\
Post-eruption & October 5, 2000 & AirSAR & SAR \\
\hline
\end{tabular}



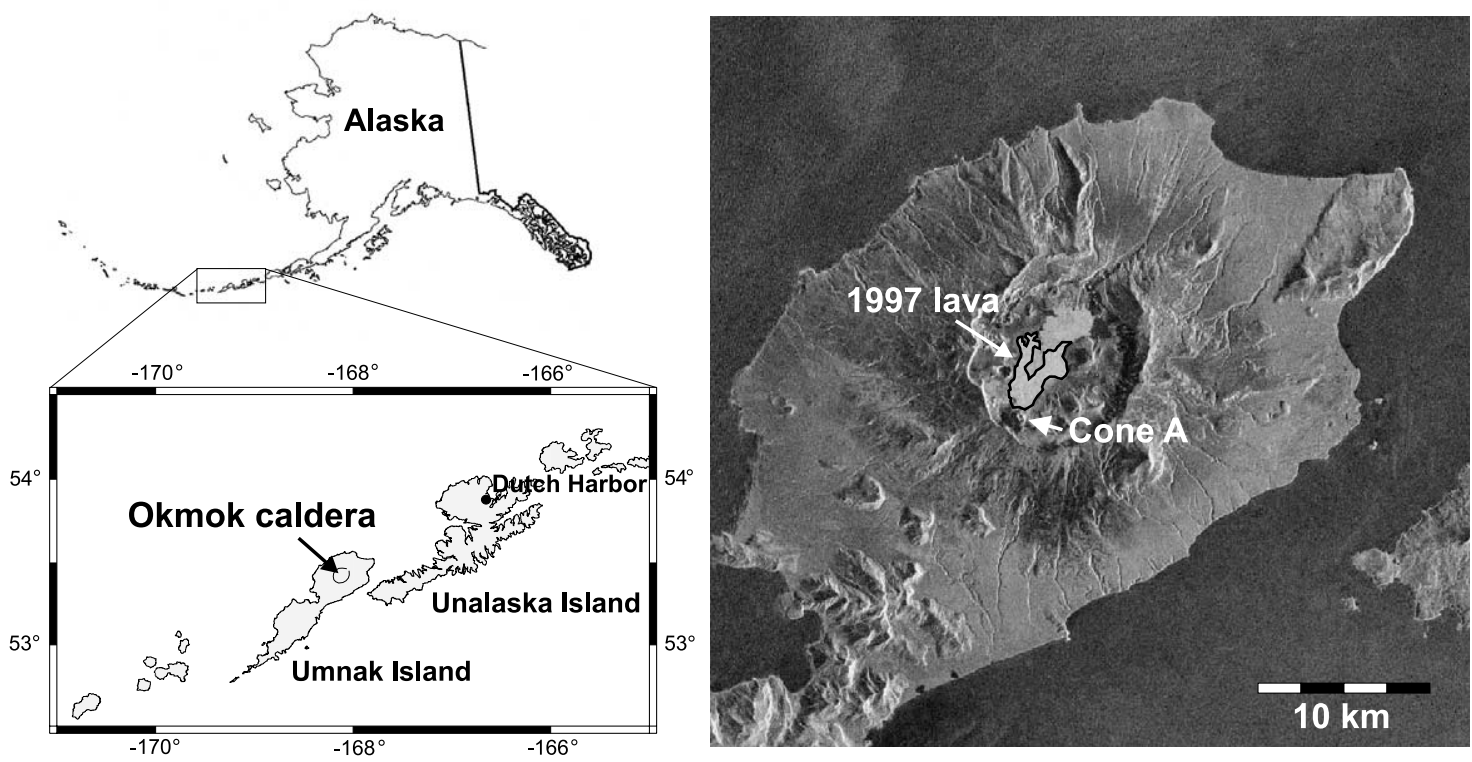

Fig. 1. Location of Okmok Volcano. Okmok Volcano is situated in the eastern Aleutian Islands, approximately $120 \mathrm{~km}$ west of Dutch Harbor. The volcano occupies most of the eastern end of Umnak Island (right). All historic activity has been restricted to within the caldera, and appears to all have originated from Cone A, in the southwest corner. The 1997 lava flow is outlined in black in the JERS SAR image.

Table 2

Sensor characteristics

\begin{tabular}{lll}
\hline Sensor & Channels & $\begin{array}{l}\text { Pixel size } \\
(\mathrm{m})\end{array}$ \\
\hline Landsat 3 MSS & $1: 0.5-0.6 \mu \mathrm{m}$ & 60 \\
& $2: 0.6-0.7 \mu \mathrm{m}$ & 60 \\
& $3: 0.7-0.8 \mu \mathrm{m}$ & 60 \\
& $4: 0.8-1.1 \mu \mathrm{m}$ & 60 \\
ERS 1+2 & $5: 10.4-12.6 \mu \mathrm{m}$ & 120 \\
AVHRR & C-band $(5.6 \mathrm{~cm})$ & 25 \\
& $1: 0.58-0.68 \mu \mathrm{m}$ & 1100 (nadir) \\
& $2: 0.725-1.1 \mu \mathrm{m}$ & 1100 (nadir) \\
& $3: 3.55-3.93 \mu \mathrm{m}$ & 1100 (nadir) \\
& $4: 10.3-11.3 \mu \mathrm{m}$ & 1100 (nadir) \\
Radarsat-1 & $5: 11.4-12.4 \mu \mathrm{m}$ & 1100 (nadir) \\
JERS-1 & C-band $(5.6 \mathrm{~cm})$ & 30 \\
Landsat 7 ETM+ & L-band $(23.5 \mathrm{~cm}$ ) & 18 \\
& $1: 0.45-0.52 \mu \mathrm{m}$ & 30 \\
& $2: 0.52-0.60 \mu \mathrm{m}$ & 30 \\
& $3: 0.63-0.69 \mu \mathrm{m}$ & 30 \\
& $4: 0.76-0.90 \mu \mathrm{m}$ & 30 \\
AirSAR & $5: 1.55-1.75 \mu \mathrm{m}$ & 30 \\
& $6 \mathrm{a}: 10.4-12.5 \mu \mathrm{m}$ (high gain) & 60
\end{tabular}


tains a number of cinder cones. All historic activity seems to have originated from Cone A, located in the southwest corner of the caldera. In addition to several poorly documented explosive events, such as the 1817 eruption which buried a nearby Aleut village, recent major eruptions have been recorded in 1945 and 1958 (Coats, 1950; Miller et al., 1998). Both of these 20th century eruptions were effusive in nature and involved extrusion of blocky basaltic lava flows, with the 1958 flow traversing nearly the entire span of the caldera to impound a lake against the far wall. Minor explosive events, originating from Cone A, were reported by pilots in 1981, 1983 and 1987 (Simkin and Siebert, 1994; Miller et al., 1998).

The latest eruption began around February 11, 1997 when pilots observed steam and a possible ash plume originating from inside the caldera (McGimsey and Wallace, 1999). Moderate Hawaiian and Strombolian activity and small ash plumes emanating from Cone A on February 13 were confirmed by additional pilot reports and satellite imagery. On February 20, Fort Glenn ranchers observed a red glow reflected off clouds, indicating lava effusion, and several days later a rancher climbed to the rim to observe a flow extending approximately $1-1.5 \mathrm{~km}$. The thermal anomaly in AVHRR imagery continued to enlarge in size, eventually covering much of the caldera. NOAA researchers photographed the flow on February 28, at which point one lobe of the compound flow extended almost $6 \mathrm{~km}$. On March 11, a pilot observed an ash plume up to $9 \mathrm{~km}$, the highest of the eruption, leading to an air traffic advisory. By March 27 visual observations indicated that activity had declined markedly, and this was confirmed by satellite imagery. Major activity had ceased by mid April according to pilot reports, satellite imagery, and observers on the ground while steam emissions and occasional minor ash explosions occurred for several more months. Products of the eruption included several ash plumes and associated ash-fall, and the $6 \mathrm{~km}$ long basaltic a'a lava flow, composed of two major lobes (Figs. 2 and 3). The first (east) lobe extended to the base of and slightly beyond Cone $\mathrm{D}$, while the second (west) lobe traveled along the base of Cone E.

\section{Pre-eruption imagery}

Pre-1997 data were used to assess the state of the caldera before the eruption. Multispectral
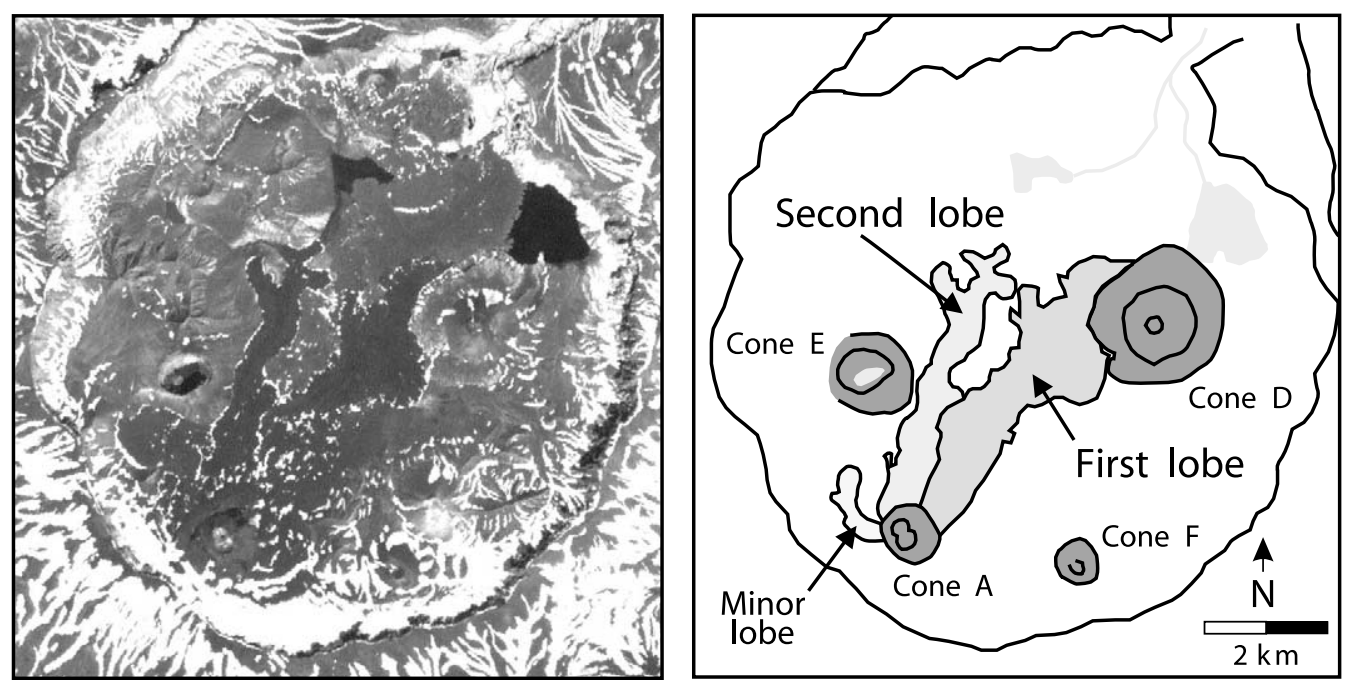

Fig. 2. Features of Okmok caldera. The panchromatic Band 8 Landsat 7 ETM+ image on the left offers a detailed view of the volcano. On the right is a simple map of the equivalent area showing the major features, and the major lobes of the 1997 flow. The first lobe flowed until it compressed against the terrace at the base of Cone D. The second lobe skirted the base of Cone E. A minor lobe, extruded in the very initial stages of the eruption, traveled a short distance west of Cone A. 

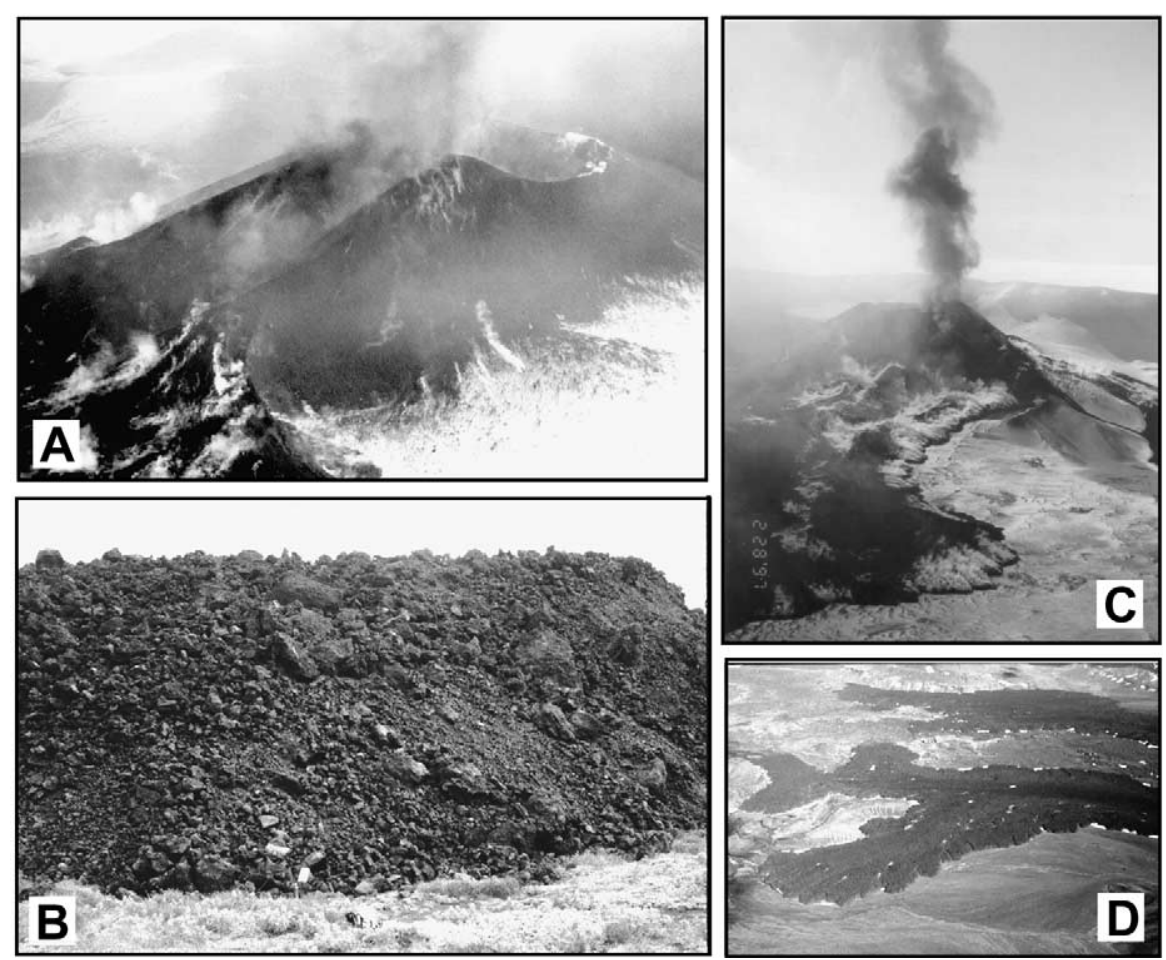

Fig. 3. Photographs of the 1997 eruption and flow. (A) Lava fountaining inside Cone A on February 28, 1997. Courtesy of John Sease, NOAA. (B) Flow front of the second lobe of the 1997 flow. Backpack for scale. Courtesy of Doerte Mann, AVO. (C) View down the nascent first lobe, towards Cone A, on February 28, 1997. Note extensive steaming at the flow front. Courtesy of John Sease, NOAA. (D) Distal ends of the second lobe (foreground) and first lobe (background), looking towards Cone D from Cone E.

(Landsat MSS) and SAR (ERS-1 and ERS-2) imagery afforded views of the caldera floor showing the 1958 and 1945 flows, and permitted us to see what surfaces were later inundated during the 1997 eruption. The 1995 ERS-2 image (Fig. 4) shows a large high-backscatter portion within the caldera extending from the southwest (near Cone A) to the northeast (near the outlet of the caldera). This region of high backscatter coincides with a lava flow field composed of the 1958 and 1945 flows, the latter shown on Byers' (1959) geologic map. The 1958 flow forms the bulk of this area, and is fringed on the east by the narrow 1945 flow. Comparing the known position of the 1997 flow (Fig. 2) to the 1995 ERS-2 image, it is clear that the 1997 flow moved directly over the existing lava field, following the same route of the other recent flows down the prevailing NE-trending slope.
$\mathrm{Lu}$ et al. (in press) produced a series of four DEMs from a total of eight ERS-1 and ERS-2 images acquired between August 1993 and October 1995. In order to eliminate errors unique to a single DEM, a baseline-weighted approach was used to combine the four individual DEMs into a single composite DEM.

\section{Co-eruption imagery}

With large-scale effusion lasting just one month, the available imagery covering the effusion period was limited. AVHRR data provided the best coverage due to its relatively high temporal resolution (up to eight passes daily over the Aleutians) at $1.1 \mathrm{~km}$ spatial resolution at nadir (Table 1; Kidwell, 1991). These data are received by a ground station at the Geophysical Institute, 


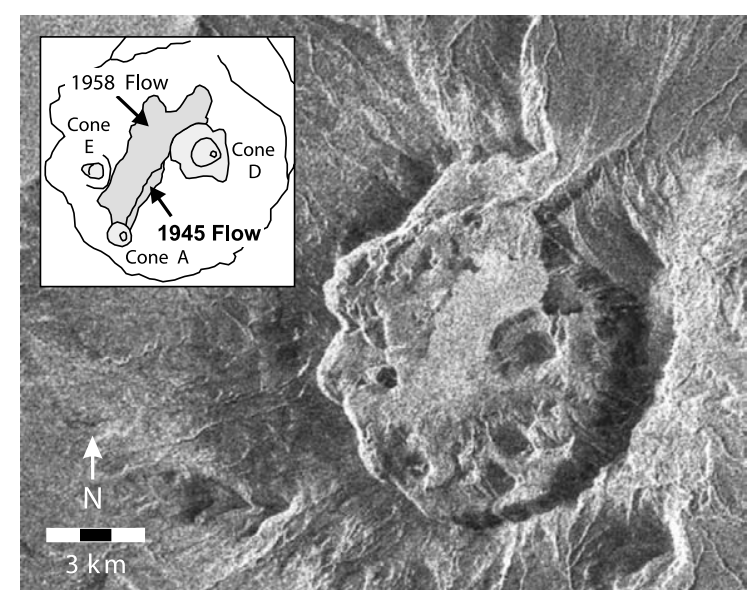

Fig. 4. ERS-2 SAR image of Okmok Volcano, from October 26, 1995. Cone A is visible in the SW corner, and the long 1958 flow can be seen traversing nearly the entire diameter of the caldera. The 1945 flow comprises a sliver of lava on the east side of the 1958 flow.

University of Alaska Fairbanks, in real time (Dean et al., 1998; Dehn et al., 2000). One or two Landsat Thematic Mapper scenes (with a repeat period of about 16 days) should have been available during the eruption, however, TM data were not archived over the Aleutian arc for most of the 1990s. Geostationary Operational Environmental Satellite (GOES) data are received at a frequency of $15 \mathrm{~min}$ at $\mathrm{AVO}$, but the oblique look angle at high latitudes renders a pixel size much larger than the nadir dimension of $4 \mathrm{~km}$. Though effective at characterizing large ash plumes, GOES data did not prove useful for surface temperature measurement in this study because of the excessively large pixel size. Finally, no SAR imagery was acquired over the caldera during February or March. As a result, AVHRR was our sole source of information during the effusion period.

The AVHRR data were analyzed in two ways. First, the morphological aspects of the thermal anomalies were examined. Second, a time series of maximum band temperature in each image was produced and analyzed.

\subsection{Morphology of the thermal anomalies}

The five spectral channels of AVHRR span the visible, near-infrared and thermal infrared portions of the spectrum (Table 2). We concentrate on Band $3(3.55-3.93 \mu \mathrm{m})$ and Band 4 (10.4-11.4 $\mu \mathrm{m})$, as these bands are closest to the peak emittance wavelengths of active lava and cool ground, respectively. Fig. 5 shows the relationship between the area of active lava in a pixel and the resulting pixel-integrated temperature, which is the result of an area-weighted average of background radiance (background temperature is $0^{\circ} \mathrm{C}$ in Fig. 5) and lava radiance. Three values are shown for lava surface temperature, which span the range of possible values for average lava surface temperature (which itself is an area-weighted composite of the radiance of incandescent cracks and cooling crust; Crisp and Baloga, 1990). A temperature of $1000^{\circ} \mathrm{C}$ would approximate a fully incandescent surface, while a value of $250^{\circ} \mathrm{C}$ would represent an a'a lava surface with a well-developed crust (Crisp and Baloga, 1990). Since Band 3 is highly sensitive to radiance from hot surfaces (hundreds of degrees Celsius), very little of the hot surface is required to produce a pixel-inte-

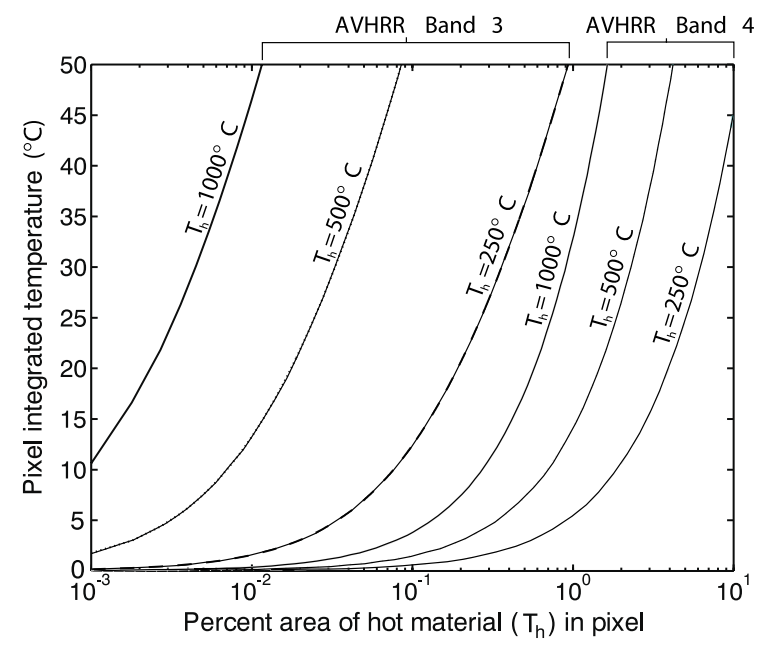

Fig. 5. Sensitivity of AVHRR Bands 3 and 4 to high-temperature surfaces. For an assumed background temperature of $0^{\circ} \mathrm{C}$, the pixel-integrated temperature is shown here for three high-temperature surfaces $\left(1000,500,250^{\circ} \mathrm{C}\right)$, for both Bands 3 and 4 . Band 4 requires a much higher percentage of hot material than Band 3 (two orders of magnitude for $T_{\mathrm{h}}=1000^{\circ} \mathrm{C}$ ) for a given pixel-integrated temperature. Band 4 , therefore, is better suited to study areal extent of erupting lava. Band 3 tends to reach saturation $\left(\sim 50^{\circ} \mathrm{C}\right)$ for even very small areas of hot material, rendering it less useful. 
grated saturation temperature of $50^{\circ} \mathrm{C}$ (Harris et al., 1997b). Pixels which are highly radiant in Band 3, therefore, may contain only minuscule portions of hot material, meaning the size of the Band 3 anomaly may be a vast overestimate of the area of active lava. Band 4, however, is less sensitive than Band 3 to high-temperature radiance and requires much more hot surface area to significantly elevate the pixel-integrated temperature, leading to the Band 4 anomaly size being a more accurate representation of recently emplaced lava coverage. It is not the aim here to measure lava flow area from pixel counts, as warned against by Harris et al. (1999) for a variety of reasons including pixel footprint overlap, but rather to simply estimate the rough extent of the lava using the radiant response of the pixels.

Fig. 6 shows the spatial variations of the thermal anomalies in selected AVHRR imagery. The eruption began without measurable precursory thermal activity on February 13, with a Band 3 thermal anomaly just a few pixels in size. No Band 4 anomaly was evident at this point, attesting to the superiority of Band 3 for detecting eruption commencement involving emergent thermal features. Harris et al. (1997c) have also shown that infrared satellite imagery can be extremely effective at detecting eruption onsets. The Band 3 anomaly had enlarged significantly by March 7, and a small Band 4 anomaly appeared. In both bands, elongation of the anomaly was generally directed to the northeast of Cone A, indicating growth of the first lobe. The February 28 visit by NOAA personnel confirmed that at least up to February 28, only the first lobe was extruding (Fig. 3C). By March 11, the Band 3 anomaly had increased in size and the Band 4 anomaly had lengthened, from further growth of the first lobe. On March 12 the Band 3 and 4 anomalies widened and extended more to the north of Cone A, which we interpret to represent eruption of the second lobe. This is supported by the March 11 pilot report of the highest ash plume of the eruption occurring on this date, pointing to a major effusive event around this time. In subsequent images, the pixel temperatures over the first lobe remained elevated, sug- gesting this lobe remained active during the eruption of the second lobe. By mid March the anomaly reached its maximum size and large-scale effusion appears to have ended, and was certainly over by March 25 . The anomaly then began rapidly diminishing in intensity as a result of cooling of the flow surface (Patrick et al., in review). Faint thermal anomalies were observed regularly throughout the next 6 months, with the last recorded anomaly of 1997 occurring in October.

\subsection{AVHRR maximum temperature time series}

The sequence of the eruption is also expressed in time series plots of the maximum pixel-integrated radiant temperature at the volcano in Bands 3 and 4 (Fig. 7). These values were extracted manually from all cloud-free, nighttime images over the volcano, as opposed to the automated technique (Dean et al., 1998; Dehn et al., 2000) which occasionally registers cloud-top temperatures. Temperature values are calculated by inserting the at-satellite radiance into the inverse Planck function, and are meant only to be approximations of the integrated surface temperature as they lack atmospheric and emissivity corrections. The Band 3 values show a sudden rise in maximum temperature on February 13 resulting from the first scene with anomalous activity and represent the onset of the eruption. The temperatures rise from background (around $5^{\circ} \mathrm{C}$ ) to approximately $49^{\circ} \mathrm{C}$, which marks the sensor saturation point in Band 3 (Harris et al., 1995). Band 4 values drop around March 25, while Band 3 values drop approximately 2 weeks later, around April 10. Determining the point at which largescale effusion ceased once again requires consideration of the differential sensitivity of Bands 3 and 4 to high temperatures. Because Band 3 is more sensitive to extremely small, high-temperature targets, it would more readily respond to the minor near-vent activity which was observed by pilots around Cone A following lava emplacement. The Band 4 data, however, will experience very little response from the vent activity due to the small areas involved. In this case, the drop in maximum Band 4 temperature will more likely represent cooling of the flow surface and the 
B3
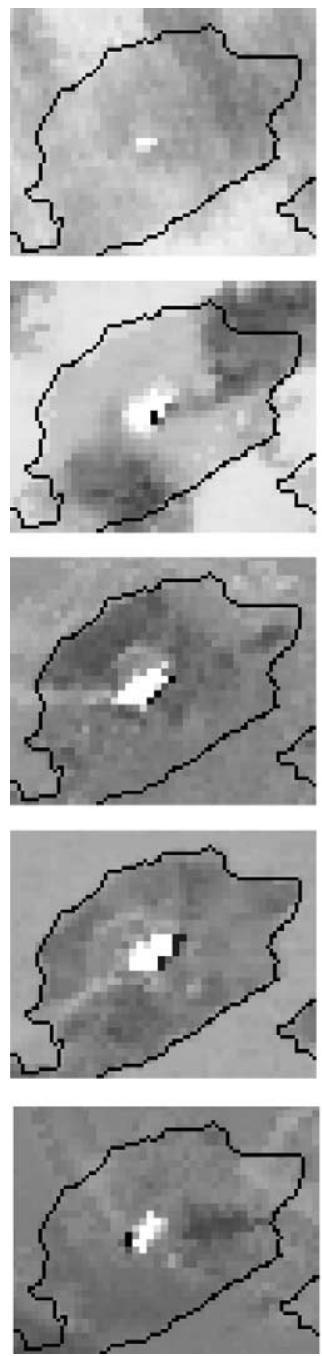

B4
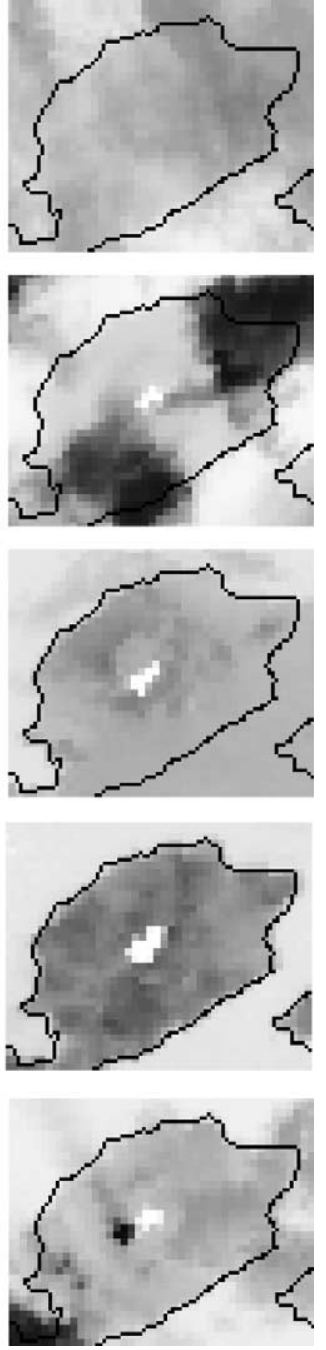

Feb 13: Start of eruption

Mar 7: Eruption of first lobe

Mar 11: Lengthening of first lobe

Mar 12: Eruption of second lobe

\section{Mar 25: End of eruption}

Fig. 6. Chronology of the eruption in AVHRR. The first thermal anomaly in AVHRR appeared in an image acquired at 1350 UTC on February 13. The anomaly is just a few pixels in size in Band 3, with no significantly anomalous pixels in Band 4. By March 7, the Band 3 anomaly had enlarged significantly and anomalous radiance had emerged in Band 4. Notice the Band 4 anomaly is limited to the area northeast of Cone A, representing eruption of the first lobe. On March 11 the Band 3 anomaly had enlarged further, and the Band 4 anomaly had lengthened but was still directed northeast of Cone A. March 12 marked a change in the shape of the anomaly. The Band 3 anomaly is roughly similar to the March 11 anomaly in size, but the Band 4 anomaly had widened, extending more to the north than the previous day. This change in shape size of the Band 4 anomaly marks the beginning of eruption of the second lobe. By March 25, the Band 3 and Band 4 anomalies had decreased in size and intensity, indicating that large-scale effusion had ended and the flow had begun cooling.

end of large-scale effusion around March 25, agreeing with the date determined by the spatial inspection of the anomalies in Section 4.1. This also agrees with visual observations from the ground pointing to large-scale activity declining by March 27. Relating these data to the visual observations, it appears that for this eruption there were essentially two stages to eruption cessation. The first entailed the end of large-scale effusion, when lava was no longer being erupted, 


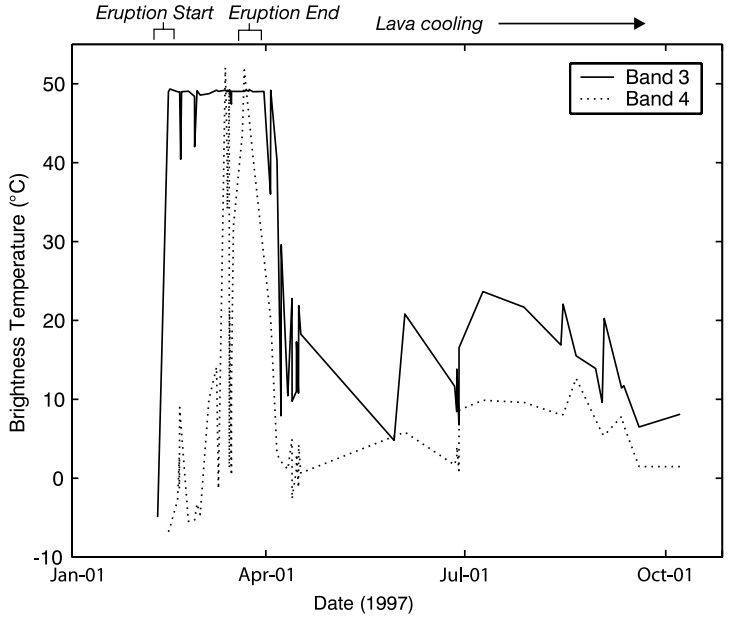

Fig. 7. Maximum band temperature in each nighttime, relatively cloud-free AVHRR image acquired during the eruption and subsequent cooling period. Temperatures in Band 3, which are sensitive to very small amounts of high-temperature material, rose dramatically on February 13 marking the start of the eruption. Band 3 immediately reached saturation $\left(\sim 50^{\circ} \mathrm{C}\right)$. Band 4 , requiring more area of hot material to raise its temperature, approached its saturation $\left(\sim 60-70^{\circ} \mathrm{C}\right)$ only when the flow attained its maximum size towards the end of the eruption ( $\sim$ March 20$)$. At this point, Band 4 values dropped marking the end of lava effusion. Band 3 temperatures remained elevated until April 10 due to events at Cone A. From about March 25 onward, the bulk of the lava flow began cooling.

and the second involved the end of remnant hightemperature activity that was observed near the vent. While the extreme sensitivity of Band 3 is useful for determining the absolute end of the latter, as shown by Aries et al. (2001), this case demonstrates that Band 4 data better represent changes in large-scale effusive behavior. The end of effusion is a more relevant parameter for our purposes here, and probably more relevant in general, compelling a re-examination of the utility of Band 3 data for eruption cessation. The anomaly steadily declined in intensity throughout the summer and by October had diminished to within a few degrees of background, being barely visible.

Using time series of both the imagery and their extracted maximum temperatures the rough chronology of the eruption was determined from our AVHRR data collection. Activity began suddenly around February 13 with the eruption of the first lobe, and it appeared to be fed throughout the majority of the eruption. This activity escalated until the eruption of the second lobe around March 12, enlarging the flow field and the resulting thermal anomaly. By March 25, large-scale lava effusion had ceased and the flow began cooling.

\section{Post-eruption imagery}

High-spatial-resolution imagery permitted a detailed assessment of the post-eruptive landforms in Okmok caldera. SAR and Landsat ETM+ imagery were used to investigate the extent of the lava flow, and a high-resolution AirSAR DEM was used to measure lava surface features.

\subsection{SAR data}

An ERS-2 image, acquired on April 3, 1997 provided the first high-resolution view of the new lava flow (Fig. 8). Along with subsequent SAR imagery that year, the image clearly showed the two-lobed flow extending to the northeast of Cone A, approximately across two thirds of the length of the caldera. The April SAR images, from both ERS-2 and Radarsat sensors, show the 1997 flow exhibiting a higher level of backscatter compared to the 1958 flow. ERS-2 and Radarsat imagery from two to three months later (midsummer) lack this contrast, and show virtually no backscatter difference between the 1958 and 1997 flows, suggesting the differing level of backscatter in the April scenes was due to differences in snow cover. Confirming this, aerial photographs from an April overflight show a continuous blanket of snow covering all of the caldera with the exception of the newly formed, and still warm, 1997 flow. A similar condition was observed in a March 19, 1992 SAR image over the newly erupted lava flow at Westdahl volcano in the Aleutian Islands (Dean et al., 2002b).

The JERS image (Fig. 8), at $24 \mathrm{~cm}$ wavelength (L-band), shows particularly high backscatter contrast between lava (the 1997, 1958 and other flows) and the remainder of the caldera surfaces, which are primarily composed of ash and alluvium. The C-band data (ERS-2 and Radarsat) lack such contrast between lava and ash/alluvium, con- 

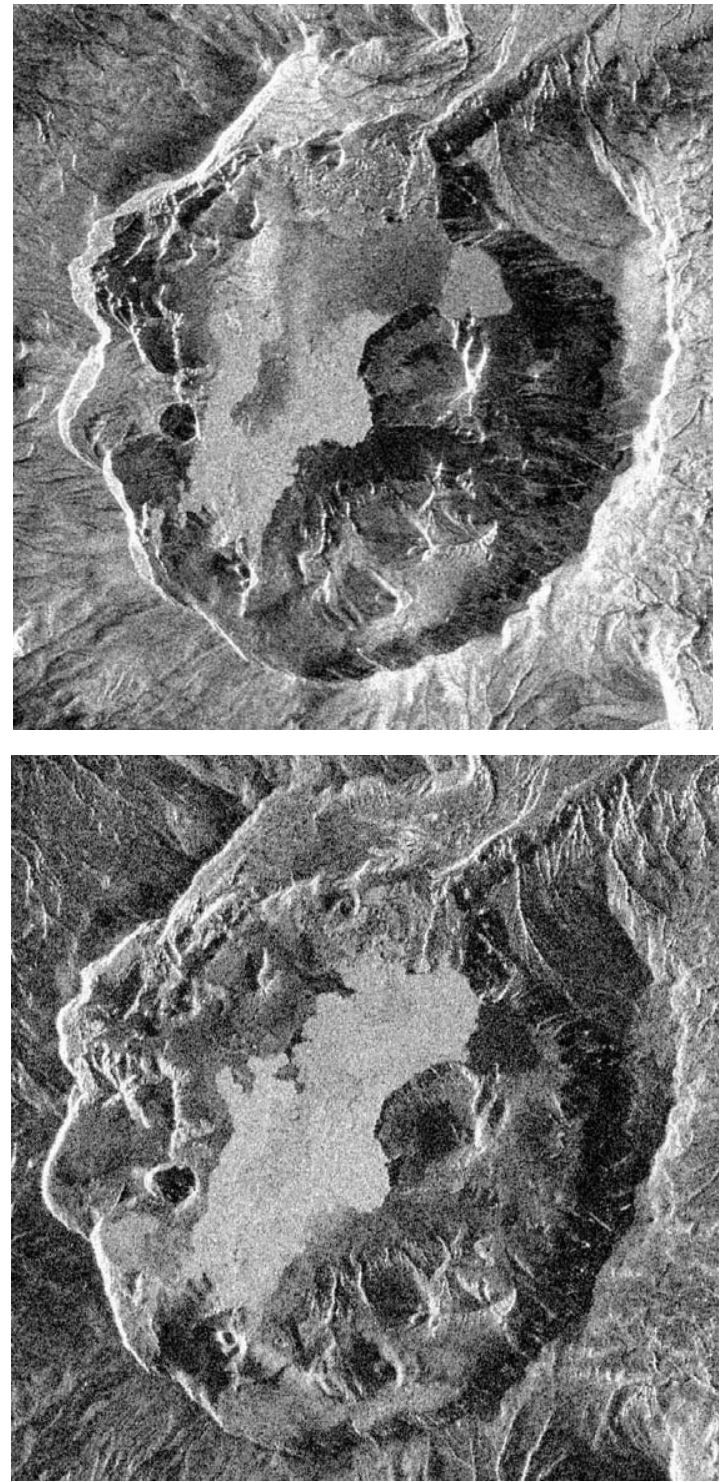

Fig. 8. Post-eruption SAR imagery. An ERS-2 SAR image (top), acquired on April 3, 1997, was the first SAR image to be acquired after the eruption. The 1997 flow exhibits higher backscatter than other features in the caldera, as well as the other recent lava flows, due to its absence of snowcover. A JERS-1 SAR image from November 5, 1997 (bottom), shows the high backscatter for all the recent lava flows compared to the rest of the caldera, due to differences in surface roughness.

sistent with the observations of Gaddis (1992) at Pisgah volcanic field. Backscatter is a function of a number of factors, including roughness, slope, dielectric properties, and instrument parameters such as wavelength, polarization and incidence angle. With other factors being equal, surfaces with a large amount of wavelength-scale roughness features will exhibit higher backscatter. Gaddis (1992) found that L-band data provided the best discrimination of lava flows due to the range of roughness dimensions on pahoehoe and $\mathrm{a}^{\prime} \mathrm{a}$ flows. Whereas most of the surface in the Pisgah volcanic field were uniformly rough at 5.6 wavelengths, making them less distinct in C-band imagery, scattering differences in L-band imagery were more pronounced. The situation appears to be similar in our collection of SAR data over Okmok.

Variations in backscatter have been investigated as a tool to garner relative ages of lava flows under the premise that older, more weathered lava flows will have a measurable difference in surface roughness compared to newly effused flows (Dean et al., 2002b; Gaddis, 1992). Gaddis (1992), however, warned that simply comparing backscatter returns may yield ambiguous results if emplacement textures and modification processes are not considered. For recent lava flows with similar morphology, backscatter has been shown to generally decrease with age (Dean et al., 2002b). It is interesting to note, therefore, that in the JERS imagery there is only the most subtle difference in backscatter between the 1997 and 1958 flows, suggesting that in this environment a weathering period of 40 years may be close to the threshold for producing noticeable backscatter differences.

\subsection{Landsat 7 ETM+}

The panchromatic Band 8 (15 m pixel size), as well as the several bands at $30 \mathrm{~m}$ pixel size, on the ETM+ sensor provided a reasonably good view of the areal extent of the flow (Fig. 2). This image, along with the NOAA overflight photos, was used to delineate the two main lobes and determine their respective length and area. The first lobe extends approximately $6.0 \mathrm{~km}$ northeast of Cone A, wrapping around the terrace at the base of Cone D. The second lobe extends $5.1 \mathrm{~km}$ in a more northerly direction. A subordinate lobe ex- 
tends just $1.4 \mathrm{~km}$ northwest of Cone A. Topographical constraints on the flow are also well exhibited. The first lobe appears to have been ponded against the terrace at the base of Cone $\mathrm{D}$, around which it was partially diverted. The second lobe encountered a series of small pyroclastic cones at its distal end that successively bifurcated the flow front, resulting in a multi-fingered terminus. Using the ETM+, we determine the total lava flow area to be approximately 8.86 $\mathrm{km}^{2}$, of which the first lobe comprises about 5.29 $\mathrm{km}^{2}$, the second lobe $3.31 \mathrm{~km}^{2}$, and the subordinate lobe about $0.26 \mathrm{~km}^{2}$.

\subsection{AirSAR DEM}

The AirSAR radar data used here were ac- quired by the TOPSAR sensor, which is a twoantenna system flown aboard a DC-8 aircraft at approximately $9 \mathrm{~km}$ asl. The baseline of the two antennas is $2.5 \mathrm{~m}$, and the radar look angles range between $30^{\circ}$ and $55^{\circ}$ of vertical $(\mathrm{Lu}$ et al., in press). The data were collected at C-band (wavelength of $5.7 \mathrm{~cm}$ ) operating at $40 \mathrm{MHz}$ range bandwidth. The resulting DEM has a pixel size of $5 \mathrm{~m}$, and an RMS height error of about 1$3 \mathrm{~m}$ (Zebker et al., 1992; Madsen et al., 1995).

The high spatial resolution and small vertical error in the DEM allowed a high-precision examination of the surface topography of the 1997 flow (Fig. 9). The most notable feature uncovered with these data was the large channel system that fed the first lobe (Fig. 9B). The main channel extends at least one half the total length of the first lobe,
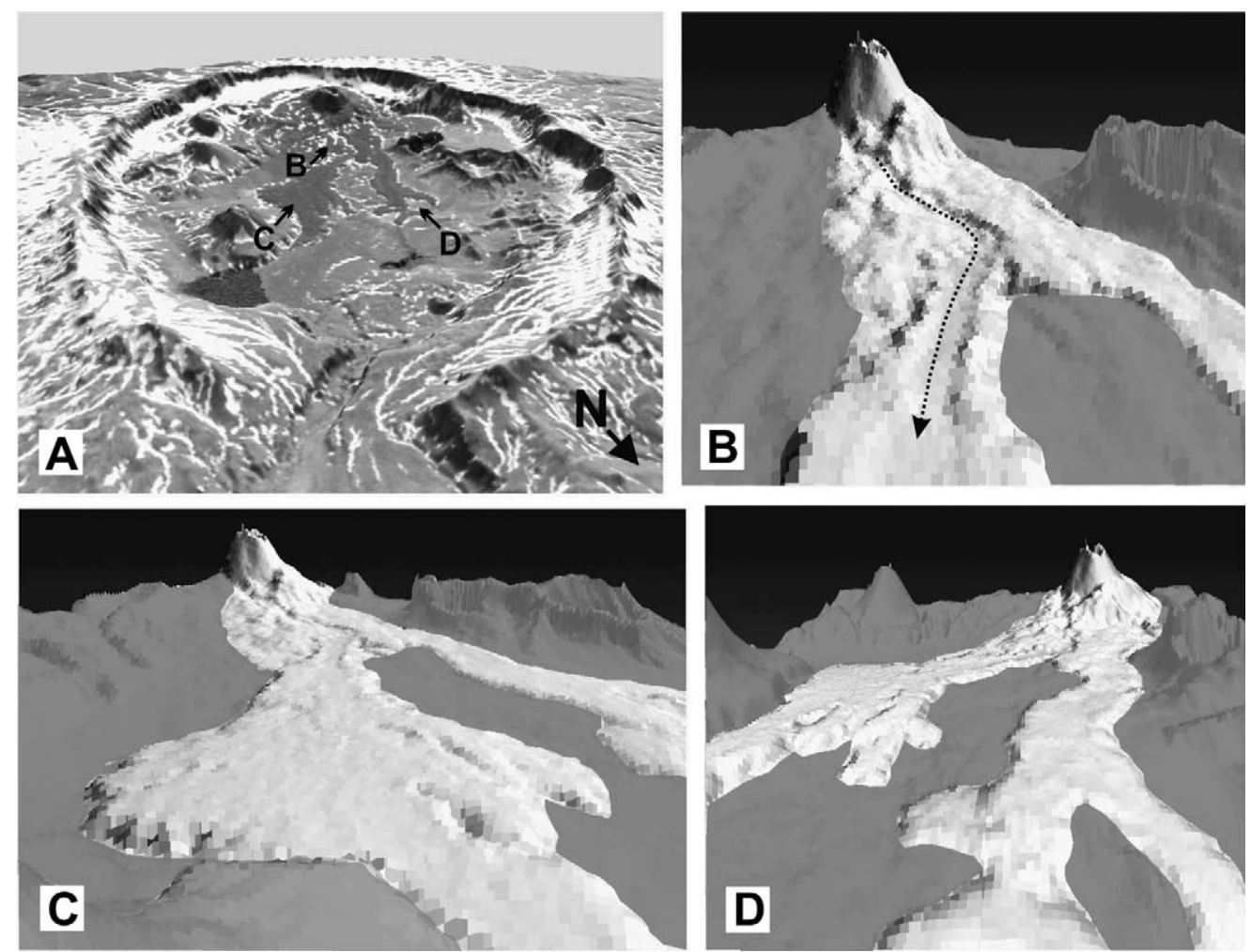

Fig. 9. Perspective views of the 1997 flow. (A) Merge of Landsat 7 ETM+ and 5-m AirSAR DEM. This view looks up Crater Creek, the entrance into the caldera, directly towards Cone A. The relatively fresh lava of the 1997 flow exhibits slightly less albedo, resulting in its darker shade in this image. Arrows and letters show the viewing direction of subfigures B-D. (B) Looking up the proximal half of the first lobe towards Cone A, the main channel is evident. Levee heights approach $10 \mathrm{~m}$. (C) From Cone $\mathrm{D}$, the impressive expanse of the first lobe is clear. In the foreground area, the flow approaches a thickness of $50 \mathrm{~m}$. (D) The second lobe bifurcated at its flow front when it encountered a series of small hills. 
and no doubt facilitated the extreme thickening of the distal end. The channel width averages approximately $200 \mathrm{~m}$ and levee heights extend up to $10 \mathrm{~m}$. Distinct levees are present on the second lobe only at the very proximal portions, within $1 \mathrm{~km}$ of Cone A, where underlying slopes are very steep $\left(6-17^{\circ}\right)$. Subtle levees exist on the remainder of the second lobe where the slope is more subdued $\left(1-3^{\circ}\right)$, but do not exceed $4 \mathrm{~m}$ in height. Another significant feature of the 1997 flow is the apparent layering that is present in the first lobe. Particularly visible at the very distal portions of the first lobe, the flow exhibits a thin first layer $(\sim 5-10 \mathrm{~m})$ overlain by a more massive top layer (often greater than $10 \mathrm{~m}$ ) that does not completely cover the first layer. Comparing the NOAA overflight photos with the spatial extent of the first and second layers, it appears that at least the first layer was largely emplaced by the time of the photos (February 28). The main channel, well established at this point, then continued to supply the overriding layers.

\section{Analyses}

These initial observations from the imagery provide a rough sequence of events and a context into which we can place a more refined analysis of the eruption. In particular, we were interested in using our pre- and post-eruption DEMs to examine the 1997 lava flow in three dimensions, as well as extracting as much information as possible from the AVHRR radiance data to determine a quantitative chronology of the eruption.

\subsection{DEM subtraction}

Accurate thickness data, incorporated with the Landsat $7 \mathrm{ETM}+$ image, provided an estimate for the overall volume of the flow, and were used to judge the accuracy of the AVHRR-derived effusion rates (Section 6.2). Until recently, an accurate estimate of the variations in thickness of the 1997 flow was lacking, as only a few field measurements had been made of the margin height in the years following the eruption. Furthermore, no post-eruption DEM existed and the pre-eruption
DEMs were of low resolution. Fortunately, the newly produced aforementioned pre- and posteruption DEMs are of sufficient precision for quantitative comparison. Lu et al. (in press) subtracted the pre-eruption DEM from the posteruption DEM to produce a map of lava flow thickness (Fig. 10). Considering the areal extent of the flow calculated from Landsat 7 ETM+ imagery along with this thickness map, they determined the total volume of the lava flow at 1.54 $( \pm 0.25) \times 10^{8} \mathrm{~m}^{3}$.

The difference in thickness between the first and second lobes is immediately obvious. Whereas the second lobe does not exceed $30 \mathrm{~m}$ in thickness, the first lobe ranges up to $50 \mathrm{~m}$ (Fig. 11). Of the total lava volume, approximately $70 \%$ is comprised by the first lobe while it accounts for $60 \%$ of the total lava area. The extreme thickness of the distal end of the first lobe, adjacent to the base of Cone D,

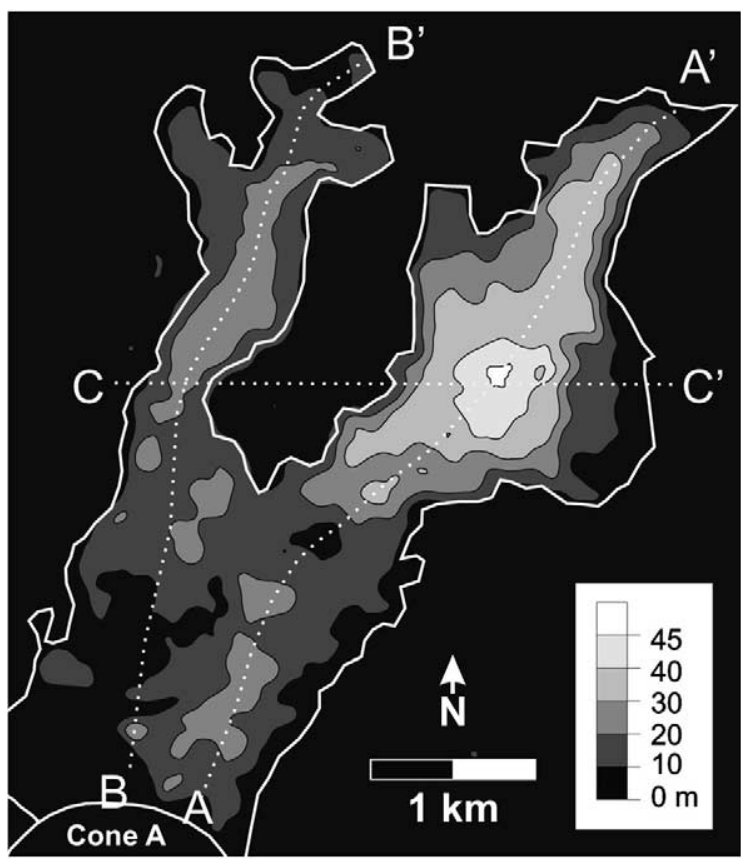

Fig. 10. Thickness of the 1997 lava flow in meters from Lu et al. (in press). These values were produced by a subtraction of the pre-eruption DEM from the post-eruption DEM. The thickness map shows the striking difference in thickness between the first and second lobes, as well as the extreme thickening that occurred at the distal portion of the first lobe due to lava ponding. The dotted lines refer to profiles in Fig. 11. 

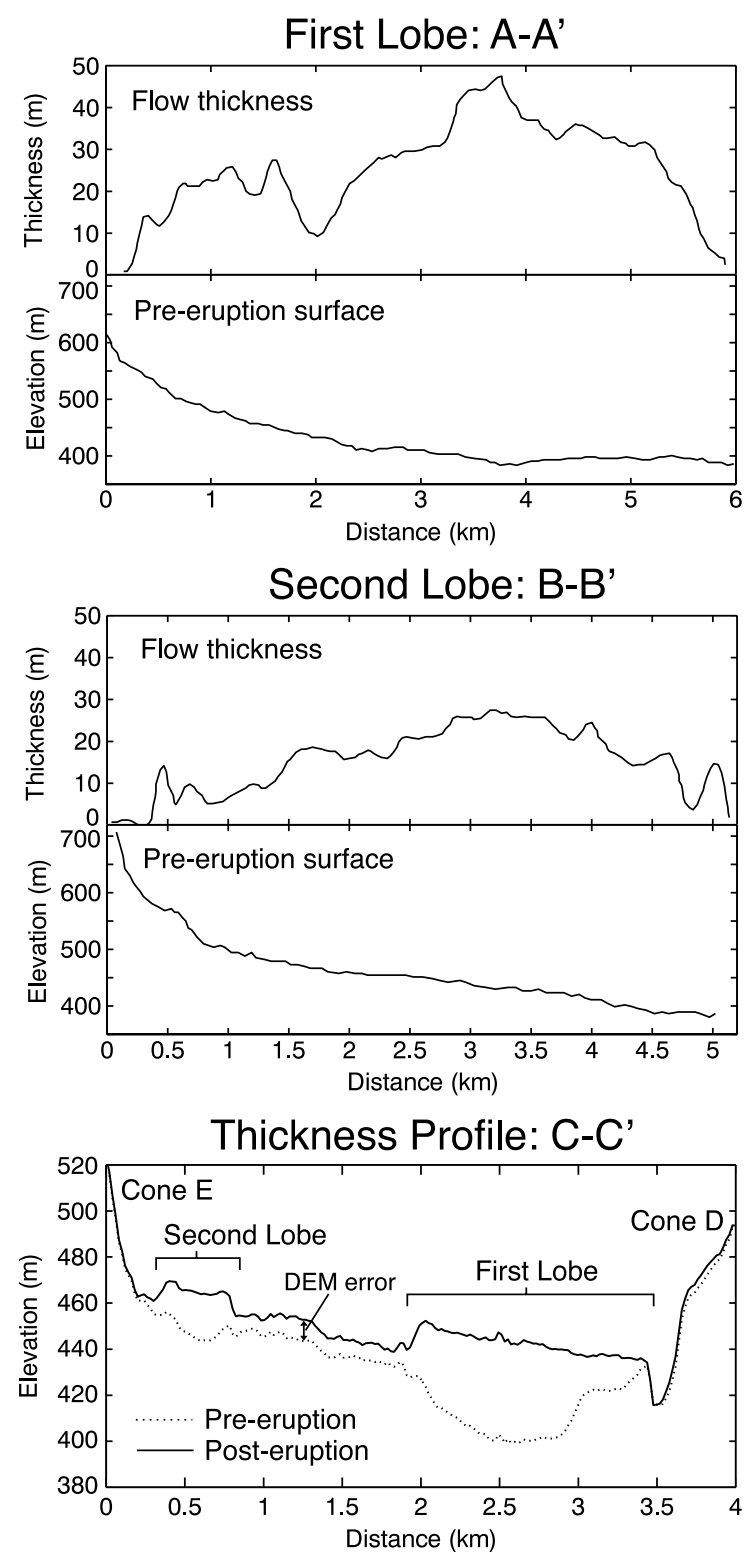

Fig. 11. Thickness profiles for the 1997 lava flow. Profiles A- $\mathrm{A}^{\prime}$ and $\mathrm{B}-\mathrm{B}^{\prime}$ are along the course of the flow, while C-C' cuts across the flow - see Fig. 10 for locations. The first lobe reached nearly $50 \mathrm{~m}$ in thickness, while the second lobe did not exceed $30 \mathrm{~m}$ in thickness. The extreme thickening of the first lobe was largely due to a pre-eruption depression (see C-C') near Cone D.

is impressive in itself. Analysis of the pre-eruption DEM indicates a large depression at this location, indicating that ponding was the main thickening mechanism. Surface folding at this distal end sug- gests that compression against the Cone $\mathrm{D}$ terrace also contributed to thickening. Thickness values up to $50 \mathrm{~m}$ are particularly surprising considering that the maximum flow margin thickness, measured in the field in August 2001, does not exceed $20 \mathrm{~m}$. The DEM-derived thickness map, therefore, with its consideration of the now hidden pre-eruption topography, was absolutely essential for accurate thickness estimates.

\subsection{AVHRR effusion rate calculations}

Radiant heat flux was calculated from AVHRR imagery in order to quantitatively assess the eruption. Only nighttime, relatively cloud-free images with scan angles less than $40^{\circ}$ were used for this purpose. From a total of over 250 images spanning the estimated length of the eruption (February 13-March 25), these criteria reduced the number to 14 useable images. Anomalous pixels in these images were defined as those having a brightness temperature of $10^{\circ} \mathrm{C}$ or more over background. To convert the at-satellite radiance to ground surface radiance, we corrected for transmissivity of the atmosphere and emissivity of the surface, as well as upwelling atmospheric radiance. Reflected radiance was assumed to be negligible in these nighttime images. The MODTRAN 4 model (Berk et al., 1999) was used to estimate transmissivity and upwelling radiance, using a sub-arctic winter atmosphere. Emissivity of the surface was assumed to be that of basalt, at 0.95 (Salisbury and D'Aria, 1994).

Harris et al. (1997a, 1998, 1999) demonstrated that relatively accurate effusion rates can be estimated using thermal satellite imagery. Wright et al. (2001a) showed that the results of this approach are actually indicative of lava flow area, and not necessarily instantaneous effusion rate. The good agreement in Harris et al. (1997a, 1998, 1999) between satellite-based effusion rates and field-measured values was due to the strong empirical correlation between eruption rate and lava area (Pieri and Baloga, 1986), and not the postulated link between satellite-derived thermal losses and actual lava flux. Regardless of its theoretical basis, the method of Harris et al. (1997a) has provided reasonably accurate effusion rates, 
and understanding the aforementioned limitations, we use it to garner a rough estimate of eruption rates in order to fill in the basic lack of knowledge on this parameter.

Using the method of Harris et al. (1997a), eruption rates were calculated using the selected AVHRR imagery described earlier (Fig. 12). In the approach, the total heat flux (both radiant and convective) is calculated and assumed to be balanced with the heat released through lava cooling, revealing mass flux (effusion rate). The effusion rate is given by:

$E_{\mathrm{r}}=\frac{Q_{\mathrm{lava}}+Q_{\mathrm{conv}}}{\rho\left[C_{\mathrm{p}} \Delta T+\phi c_{\mathrm{L}}\right]}$

where $Q_{\text {lava }}$ and $Q_{\text {conv }}$ are the radiative and convective heat flux, $\rho, C_{\mathrm{p}}, c_{\mathrm{L}}, \phi$ are density, specific heat, latent heat of crystallization, and the fraction of crystallization of the lava, respectively, and $\Delta T$ is the change between effusion temperature and solidus. The values adopted for each variable are shown in Table 3. Radiative heat loss is given by:

$Q_{\text {lava }}=\sum_{x=1}^{n}\left(\sigma \varepsilon A_{\mathrm{x}}\left[p_{\mathrm{cx}} T_{\mathrm{cx}}^{4}+p_{\mathrm{hx}} T_{\mathrm{hx}}^{4}\right]\right)$

where $\sigma$ is the Stefan-Boltzmann constant $\left(5.67 \times 10^{-8} \mathrm{~W} \mathrm{~m}^{-2} \mathrm{~K}^{-4}\right), \varepsilon$ is emissivity, $T_{\mathrm{hx}}$ and $T_{\mathrm{cx}}$ are the temperatures for the molten and crusted parts of the flow surface in each pixel, and $p_{\mathrm{hx}}$ and $p_{\mathrm{cx}}$ are their respective fractional areas. Convective heat loss is given by:

$Q_{\text {conv }}=0.14 A_{\text {lava }} k(g \alpha \rho / \mu \kappa)^{1 / 3} \Delta T_{\mathrm{s}}^{4 / 3}$

where $A_{\text {lava }}$ is area of the lava, $g$ is the acceleration due to gravity $\left(9.8 \mathrm{~m} / \mathrm{s}^{2}\right), k, \alpha, \rho, \mu, \kappa$ are the thermal conductivity, cubic expansivity, density, dynamic viscosity, and thermal diffusivity of air at the mean temperature of air and lava.

The results show an increase of effusion rate between February 13 and March 24, corresponding to enlargement of the thermal anomaly and growth of the first lobe (Fig. 12). This rise is interrupted by a sharp spike of high values around March 12 and March 13, agreeing with our morphological inspection (Section 4.1) for the time of eruption of the second lobe. After March 24, val-

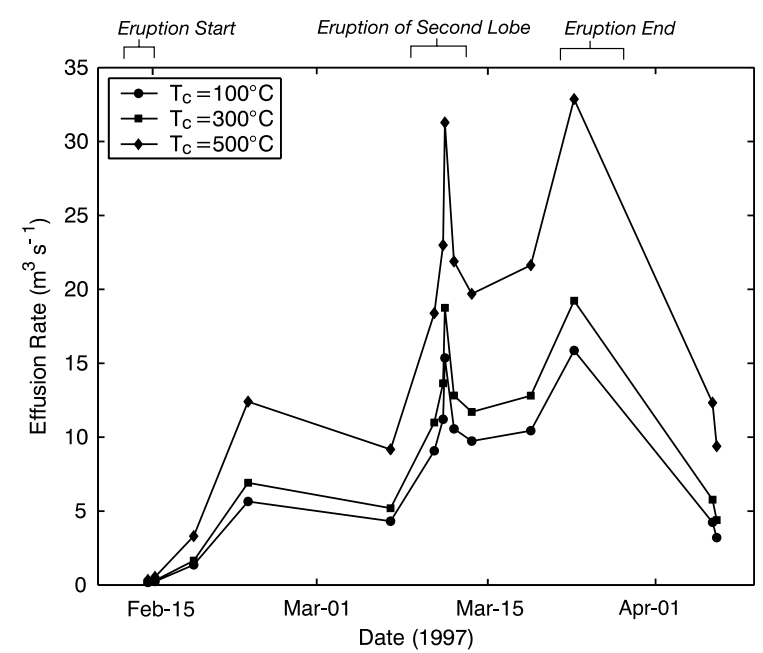

Fig. 12. Effusion rate calculation results. Although Wright et al. (2001a) have shown this space-based effusion rate calculation approach to be indicative of active lava area rather than instantaneous effusion rates, we used the technique to see if plausible estimates could be garnered. Calculations were performed using three assumed values for the temperature of the cooling crust. Unfortunately, the substantial ponding of the first lobe resulted in effusion rate results being incorrect by almost an order of magnitude. Still, the trend of the eruption is shown well, with the distinct rise and gradual increase in effusion, interrupted by a spike of high values which corresponds to the time of eruption of the second lobe. After March 25, the values drop dramatically, representing the end of the eruption.

ues decrease dramatically indicating the end of the eruption.

Integrating these effusion rates produces total volume estimates ranging between $3.3 \times 10^{7} \mathrm{~m}^{3}$ for $T_{\mathrm{c}}=100^{\circ} \mathrm{C}$ and $7.2 \times 10^{7} \mathrm{~m}^{3}$ for $T_{\mathrm{c}}=500^{\circ} \mathrm{C}$, which are, at best, approximately one half the erupted lava volume determined by the DEMproduced thickness map. Indeed, to produce the thickness-derived volume the average eruption rate would have to be approximately $46 \mathrm{~m}^{3} / \mathrm{s}$ for an eruption duration of 39 days (February 13March 24), which is much higher than the average effusion rate determined from satellite imagery $\left(\sim 8-16 \mathrm{~m}^{3} / \mathrm{s}\right)$. One or more of the following causes may be responsible for this discrepancy:

(1) A portion of the difference can be attributed to the volume difference between dense rock and bulk rock, with the former being representative of the lava in the effusion rate calculations, and the 
latter being the lava analyzed in the DEM subtraction. Using a generic correction factor of $25 \%$ volume reduction from bulk rock to dense rock (Rowland et al., 1999; Wolfe et al., 1987), a volume of $1.16 \times 10^{8} \mathrm{~m}^{3}$ can be estimated for the dense rock equivalent of the DEM subtraction. While closer to the effusion rate volume results, this value is still almost two times higher than the maximum volume estimated with that method.

(2) A plausible source of error in the effusion rate calculations originates from this method's link to lava area rather than actual volume flux (Wright et al., 2001a). In the case of the 1997 Okmok flow, substantial ponding at the distal end of the first lobe resulted in a lava flow surface area disproportionate to lava flux, leading to a breakdown in the Harris et al. (1997a) method. The lower than expected volume calculated here by their method can be explained by the flow surface area being smaller than that which would have occurred if the flow had been unimpeded. This phenomenon should be considered for future applications of the method on ponded flows.

(3) Harris et al. (2000) discuss another important reason as to why time integration of the effusion rate values may not produce realistic volume estimates. Due to the limited frequency at which the satellite data is acquired, whether due to the inherent repeat period of the satellite or the availability of cloud-free views, the imagery may not sample representative instances of the effusive behavior. It is possible that anomalously high ef- fusion rates may have occurred between satellite passes. The integration, and subsequent averaging of effusion rate values between sample points, would result in a lower volume estimate. This is especially relevant to the results here, where the lack of cloud-free scenes due to the ubiquitous cloud cover in the Aleutians has reduced the number of useable scenes to just 14 over the course of 60 days.

(4) AVHRR Band 3 is highly prone to saturation, reaching a maximum at a pixel-integrated temperature of about $49^{\circ} \mathrm{C}$ (Harris et al., 1995). In the 14 images that were used for the effusion rate calculations there was a total of 260 anomalous pixels, and of these, 126 were saturated in Band 3. The method of Harris et al. (1997a) does not disregard these pixels, but rather relies on the Band 4 data only. When using just one band, however, the unknowns must be reduced, and this is accomplished by assuming that the radiant contribution of the hot component $\left(p_{\mathrm{h}}\right)$ is insignificant in Band 4 due to its typical small size. This assumption is generally valid, but invites the possibility of error should the hot component area be larger than expected.

\subsection{Flow-limiting factors}

The thickness map (Fig. 10) and Landsat 7 ETM+ image (Fig. 2) indicate that the first lobe attained its impressive thickness through a combination of ponding in a pre-eruption depression

Table 3

Effusion rate variables

\begin{tabular}{llll}
\hline Lava & & & \\
Density $^{\mathrm{a}}$ & $\rho$ & 1950 & $\mathrm{~kg} / \mathrm{m}^{3}$ \\
Specific heat capacity & $C_{\mathrm{p}}$ & 860 & $\mathrm{~J} /(\mathrm{kg} \mathrm{K})$ \\
Latent heat & $c_{\mathrm{L}}$ & 290000 & $\mathrm{~J} / \mathrm{kg}$ \\
Fraction crystals & $\phi$ & 0.35 & $\mathrm{~K}$ \\
Temperature change & $\Delta T$ & 150 & \\
Emissivity & $\varepsilon$ & 0.99 & $\mathrm{~W} /(\mathrm{m} \mathrm{K})$ \\
Air & & & $\mathrm{K}-1$ \\
Thermal conductivity & $k$ & $2.43 \mathrm{E}+04$ & $\mathrm{~kg} / \mathrm{m}^{3}$ \\
Cubic expansivity & $\alpha$ & 0.00371 & $\mathrm{~N} \mathrm{~s} / \mathrm{m}^{3}$ \\
Density & $\rho$ & 1.278 & $\mathrm{~m}^{2} / \mathrm{s}$ \\
Dynamic viscosity & $\mu$ & $1.72 \mathrm{E}+09$ & $1.92 \mathrm{E}+07$ \\
Thermal diffusivity & $\kappa$ & & \\
\hline
\end{tabular}

\footnotetext{
a Vesicle-corrected.
} 
and compression against the Cone D terrace, and these mechanisms ultimately inhibited the forward progress of the flow front. The second lobe, however, did not encounter a substantial pre-eruption depression and could thus be either volume-limited or cooling-limited. To determine the limiting factor, we used the Gratz number and flow front cooling calculation to characterize the state of the lobe upon its termination (Wright et al., 2001b; Pinkerton and Wilson, 1994). Due to the uncertainty in many of the input variables, we solved over a range of plausible values. To be coolinglimited, the flow front would require sufficient time to solidify, and this time span can be estimated by (Kilburn, 2000):

$t=\frac{(S / \rho g)\left(\rho C_{\mathrm{p}} / \varepsilon \sigma T^{3}\right)}{\sin \beta}$

where $S$ is the energy per unit volume for failure $\left(2 \times 10^{4} \mathrm{~Pa}\right), \rho$ is the density of the lava crust (2000 kg/m 3 , considering vesicles), $g$ is the acceleration due to gravity $\left(9.81 \mathrm{~m} / \mathrm{s}^{2}\right), C_{\mathrm{p}}$ is the specific heat capacity $(1150 \mathrm{~J} / \mathrm{kg}), \mathcal{E}$ is the surface emissivity (0.9), $\sigma$ is the Stefan-Boltzmann constant $\left(5.67 \times 10^{-8} \mathrm{~W} \mathrm{~m}^{-2} \mathrm{~K}^{-4}\right), T$ is the eruption temperature, and $\beta$ is ground slope (degrees). Choosing a single value for ground slope is troublesome, since the values range from $19^{\circ}$ (proximal) to less than $1^{\circ}$ (distal) (Fig. 11). Slopes greater than $3^{\circ}$, however, are limited solely to the first kilometer of the flow, suggesting it may be suitable to solve for two mean slope values: the total mean $\left(4.2^{\circ}\right)$ and the mean for distances between 1 and $5 \mathrm{~km}\left(1.8^{\circ}\right)$. Furthermore, since eruption temperature is not well known, we solved between $1300 \mathrm{~K}$ and $1400 \mathrm{~K}$. For a temperature of 1300 $\mathrm{K}$, the flow front solidification time is 7.7 days for a mean slope of $1.8^{\circ}$, and 3.3 for a mean slope of $4.2^{\circ}$. For a temperature of $1400 \mathrm{~K}$, the solidification time is 6.2 days for a mean slope of $1.8^{\circ}$ and 2.6 days for a slope of $4.2^{\circ}$. Due to the absence of high-resolution imagery acquired during the eruptive period, there is no way to establish precisely the effusive duration of the second lobe, but the AVHRR imagery limits it to less than approximately 14 days.

We then calculated the Gratz number, which is used to characterize the amount of heat conducted from the interior of the flow. Cooling-limited flows have been shown to have Gratz numbers around 300 (Pinkerton and Wilson, 1994). Of the several ways to calculate the Gratz number, we chose the form best suited to the information available to us:

$G r=(n d)^{2} / \kappa t$

where $d$ is the mean flow thickness $(\sim 15 \mathrm{~m}$ for the second lobe), $n=d_{\mathrm{e}} / d$ where $d_{\mathrm{e}}=\left(2 w_{\mathrm{c}} d\right) /\left(w_{\mathrm{c}}+d\right)$ and $w_{\mathrm{c}}$ is the mean channel width, $\kappa$ is the thermal diffusivity, and $t$ is eruptive duration. Solving over a range of channel widths (100-200 m, based on the DEM) and eruption durations (1-15 days) produces a maximum Gratz number of 12877 and minimum of 750, far above the expected Gratz number of $\sim 300$ for a cooling-limited flow.

The high Gratz numbers indicate that a cooling-limited situation was improbable, and, therefore, the flow was likely volume-limited. In this case, flow front solidification would not have been a limiting factor and our calculations suggest that emplacement occurred in less than 3-8 days, which is well within the 14-day maximum time period established by AVHRR. If volume-limited, and if emplacement took place within 8 days, then the second lobe may have been starved of its lava supply before the end of the eruption, while the first lobe continued to be fed. This situation is not unreasonable, as analysis of the co-eruptive photographs shows that the first lobe and a small initial lobe of lava that would later be overrun by the second lobe were each supplied by independent clefts in Cone A. Thus, it is conceivable that the spillway feeding the second lobe became inactive or was blocked, while that supplying the first lobe remained active and clear.

\section{Conclusions}

Integrating satellite data from various sensors allowed a detailed examination of the eruption and its lava flow that would not have been possible otherwise. AVHRR data were used to create a time series of the flow growth and effusion rates, and to determine the time of extrusion of the first 
and second lobes. The AirSAR DEM, in conjunction with a pre-eruption ERS SAR-derived DEM, provided a detailed map of flow thickness and lava volume, as well as lava surface morphology. SAR and Landsat ETM+ imagery were used to determine the precise aerial extent of the flow.

The important information extracted from these images includes the timing of the eruption phases, the extent and characteristics of the flow and the total volume of the lava. From an eruption start around February 13, activity increased until around March 25, punctuated by eruption of the second lobe around March 11. The resulting flow covered approximately $8.9 \mathrm{~km}^{2}$, and differed in nature between its two main lobes. The first lobe exhibited substantial channeling and ponded in a pre-eruption depression to reach a thickness of about $50 \mathrm{~m}$. The second had subdued channeling and did not exceed $30 \mathrm{~m}$ in thickness, and was probably volume-limited. The total bulk lava volume was approximately $1.54( \pm 0.25) \times$ $10^{8} \mathrm{~m}^{3}$.

Whereas satellite data have traditionally proven a useful supplement to other monitoring techniques, this study demonstrates how the data can be used to effectively track and measure effusive activity in the absence of ground-based data. Lascar volcano is another example of the standalone utility of remotely sensed data. Due to its isolated setting, much of what is known of its effusive and explosive activity over the past 25 years has been constrained solely from remotely sensed data (Oppenheimer et al., 1993; Wooster and Rothery, 1997; Matthews et al., 1997; Glaze et al., 1989).

The AVO's seismic network currently covers 25 volcanoes, leaving approximately 16 active volcanoes which must be monitored solely with satellite imagery. The eruption of Mt. Cleveland, another volcano lacking seismic coverage, in February 2001 and the successful tracking of its dramatic ash plume is another recent example of the effectiveness of remote sensing for monitoring Alaska's active volcanoes (Dean et al., 2002a). Satellite data provide easy access to the remainder of Alaska's remote volcanoes, and studies like this offer methods to better understand their eruptive behavior and products.

\section{Acknowledgements}

A number of AVO personnel should be thanked for their assistance: Doerte Mann provided useful advice on the DEMs and SAR processing, and Dela Grey provided much assistance in the field. John Eichelberger and Jeff Freymueller helped make the fieldwork possible. Thanks also go to Tim and Mala Webb of Bering Pacific Ranch on Umnak Island for information and assistance, and Jonathan Sease of NOAA for the invaluable photographs. Detailed comments from Christina Neal (AVO-USGS) and Andy Harris (University of Hawaii Manoa) very much improved the paper. Reviews by Martin Wooster (King's College London) and Luke Flynn (University of Hawaii Manoa) were greatly appreciated. This work is supported by the United States Geological Survey Volcano Hazards Program and the Geophysical Institute at the University of Alaska Fairbanks, by the funding from NASA (NRA-99-OES-10 RADARSAT-0025-0056) (to Z.L.), and by USGS Contracts O3CRCN0001 and 1434-CR-97-CN-40274 (to Z.L.). ERS-1 and ERS-2 images are copyright 1994 and 1997 ESA, and the JERS image is copyright 1995 NASDA. All SAR images were provided by the Alaska SAR Facility.

\section{References}

Aries, S.E., Harris, A.J.L., Rothery, D.A., 2001. Remote infrared detection of the cessation of volcanic eruptions. Geophys. Res. Lett. 28, 1803-1806.

Berk, A., Anderson, G.P., Bernstein, L.S., Acharya, P.K., Dothe, H., Matthew, M.W., Adler-Golden, S.M., Chetwynd, J.H. Jr., Richtsmeier, S.C., Pukall, B., Allred, C.L., Jeong, L.S., Hoke, M.L., 1999. MODTRAN4 radiative transfer modeling for atmospheric correction. SPIE Proc. Optical Spectroscopic Techniques and Instrumentation for Atmospheric and Space Research III, Volume 3756.

Black, R.F., 1975. Late Quaternary geomorphic processes: Effects on the ancient Aleuts of Umnak Island in the Aleutians. Arctic 28, 159-169.

Byers, F.M, 1959. Geology of Umnak and Bogoslof Islands, Aleutian Islands, Alaska. US Geol. Surv. Bull. 1028-L, 267369.

Coats, R.R., 1950. Volcanic activity in the Aleutian Arc. US Geol. Surv. Bull. 974-B, 1-47. 
Crisp, J., Baloga, S., 1990. A model for lava flows with two thermal components. J. Geophys. Res. 95, 1255-1270.

Dean, K., Servilla, M., Roach, A., Foster, B., Engle, K., 1998. Satellite monitoring of remote volcanoes improves study efforts in Alaska. EOS Trans. AGU 79, 422-423.

Dean, K., Dehn, J., McNutt, S., Neal, C., Moore, R., Schneider, D., 2002a. Satellite imagery proves essential for monitoring erupting Aleutian volcano. EOS Trans. AGU 83, 246-247.

Dean, K.G., Engle, K., Partington, K., Groves, J., Dehn, J., 2002b. Analysis of surface processes using SAR Data: Westdahl Volcano, Alaska. Int. J. Remote Sens. 23, 4529-4550.

Dehn, J., Dean, K., Engle, K., 2000. Thermal monitoring of North Pacific volcanoes from space. Geology 28, 755758.

Gaddis, L.R., 1992. Lava-flow characterization at Pisgah volcanic field, California, with multiparameter imaging radar. Geol. Soc. Am. Bull. 104, 695-703.

Glaze, L.S., Francis, P.W., Self, S., Rothery, D.A., 1989. The 16 September 1986 eruption of Lascar Volcano, North Chile; satellite investigations. Bull. Volcanol. 51, 149-160.

Harris, A.J.L., Rothery, D.A., Carlton, R.W., Langaas, S., Mannstein, H., 1995. Non-zero saturation of AVHRR thermal channels over high temperature targets: evidence from volcano data and a possible explanation. Int. J. Remote Sens. 16, 189-196.

Harris, A.J.L., Blake, S., Rothery, D.A., Stevens, N.F., 1997a. A chronology of the 1991 to 1993 Mount Etna eruption using advanced very high resolution radiometer data: Implications for real-time thermal volcano monitoring. J. Geophys. Res. 102, 7985-8003.

Harris, A.J.L., Butterworth, A.L., Carlton, R.W., Downey, I., Miller, P., Navarro, P., Rothery, D.A., 1997b. Low-cost volcano surveillance from space: case studies from Etna, Krafla, Cerro Negro, Fogo, Lascar and Erebus. Bull. Volcanol. 59, 49-64.

Harris, A.J.L., Keszthelyi, L.P., Flynn, L.P., Mouginis-Mark, P.J., Thornber, C.R., Kauahikaua, J.P., Sherrod, D.R., Trusdell, F.A., Flament, P., Sawyer, M., 1997c. Near-realtime monitoring of effusive volcanic eruptions from geostationary satellites. GSA Abstr. 29, 165.

Harris, A.J.L., Flynn, L.P., Keszthelyi, L., Mouginis-Mark, P.J., Rowland, S.K., Resing, J.A., 1998. Calculation of lava effusion rates from Landsat TM data. Bull. Volcanol. $60,52-71$.

Harris, A.J.L., Flynn, L.P., Rothery, D.A., Oppenheimer, C., Sherman, S.B., 1999. Mass flux measurements at active lava lakes: Implications for magma recycling. J. Geophys. Res. 104, 7117-7136.

Harris, A.J.L., Murray, J.B., Aries, S.E., Davies, M.A., Flynn, L.P., Wooster, M.J., Wright, R., Rothery, D.A., 2000. Effusion rate trends at Etna and Krafla and their implications for eruptive mechanisms. J. Volcanol. Geotherm. Res. 102, 237-270.

Kidwell, K.B., 1991. NOAA Polar Orbiter Data User's Guide. NOAA National Environmental Satellite, Data, and Information Service, Washington, DC.
Kilburn, C.R.J., 2000. Lava flows and flow fields. In: Sigurdsson, H., Houghton, B., McNutt, S., Rymer, H., Stix, J. (Eds.), Encyclopedia of Volcanoes. Academic Press, London, pp. 291-305.

Lu, Z., Fielding, E., Patrick, M., Trautwein, C., in press. Estimating lava volume by precision combination of multiple baseline spaceborne and airborne interferometric synthetic aperture radar: the 1997 eruption of Okmok volcano, Alaska. IEEE Trans. Geosci. Remote Sens.

Madsen, S.N., Martin, J.M., Zebker, H.A., 1995. Analysis and evaluation of the NASA/JPL TOPSAR across-track interferometric SAR system. IEEE Trans. Geosci. Remote Sens. 33, 383-391.

Matthews, S.J., Gardeweg, M.C., Sparks, R.S.J., 1997. The 1984 to 1996 cyclic activity of Lascar Volcano, northern Chile; cycles of dome growth, dome subsidence, degassing and explosive eruptions. Bull. Volcanol. 59, 72-82.

McGimsey, R., Wallace, K.L., 1999. 1997 volcanic activity in Alaska and Kamchatka: Summary of events and response of the Alaska Volcano Observatory. USGS Open File Report 99-448.

Miller, T.P., Smith, R.L., 1987. Late Quaternary caldera-forming eruptions in the eastern Aleutian arc, Alaska. Geology $15,434-438$.

Miller, T.P., McGimsey, R.G., Richter, D.H., Riehle, J.R., Nye, C.J., Yount, M.E., Dumoulin, J.A., 1998. US Geological Survey Open-File Report 98-582. Alaska Volcano Observatory, Anchorage, AK

Moxey, L., Dehn, J., Papp, K., Patrick, M., Guritz, R., 2001. The 1997 eruption of Okmok volcano, Alaska, a synthesis of remotely sensed data. Abstract, AGU Fall Meeting.

Oppenheimer, C., Francis, P.W., Rothery, D.A., Carlton, R.W.T., Glaze, L.S., 1993. Infrared image analysis of volcanic thermal features; Lascar Volcano, Chile, 1984-1992. J. Geophys. Res. 98, 4269-4286.

Patrick, M., Dehn, J., Dean, K., in review. Numerical modeling of lava flow cooling applied to the 1997 Okmok eruption, I: Approach and analysis. J. Geophys. Res.

Pieri, D.C., Baloga, S.M., 1986. Eruption rate, area, and length relationships for some Hawaiian lava flows. J. Volcanol. Geotherm. Res. 30, 29-45.

Pinkerton, H., Wilson, L., 1994. Factors controlling the lengths of channel-fed lava flows. Bull. Volcanol. 56, 108120.

Rowland, S.K., MacKay, M.E., Garbeil, H., Mouginis-Mark, P.J., 1999. Topographic analyses of Kilauea Volcano, Hawaii, from interferometric airborne radar. Bull. Volcanol. 61, 1-14.

Salisbury, J.W., D’Aria, D.M., 1994. Emissivity of terrestrial materials in the 3-5 $\mu \mathrm{m}$ atmospheric window. Remote Sens. Environ. 47, 345-361.

Simkin, T., Siebert, L., 1994. Volcanoes of the World. Geoscience Press, Tucson, AZ.

Wolfe, E.W., Garcia, M.O., Jackson, D.B., Koyanagi, R.Y., Neal, C.A., Okamura, A.T., 1987. The Puu Oo eruption of Kilauea Volcano, episodes 1-20, January 3, 1983, to June 8, 1984. USGS Prof. Pap. 1350, 471-508. 
Wooster, M.J., Rothery, D.A., 1997. Thermal monitoring of Lascar Volcano, Chile, using infrared data from the alongtrack scanning radiometer; a 1992-1995 time series. Bull. Volcanol. 58, 566-579.

Wright, R., Blake, S., Harris, A.J.L., Rothery, D.A., 2001a. A simple explanation for the space-based calculation of lava eruption rates. Earth Planet. Sci. Lett. 192, 223-233.
Wright, R., Flynn, L.P., Harris, A.J.L., 2001b. Evolution of lava flow-fields at Mount Etna, 27-28 October 1999, observed by Landsat 7 ETM+. Bull. Volcanol. 63, 1-7.

Zebker, H.A., Madsen, S.N., Martin, J., Wheeler, K.B., Miller, T., Lou, Y., Alberti, G., Vetrella, S., Cucci, A., 1992. The TOPSAR interferometric radar topographic mapping instrument. IEEE Trans. Geosci. Remote Sens. 30, 933-940. 